\title{
Dietary diversity and nutritional status of 2 to 5 years old children in households with and without home gardens in selected districts in Siem Reap province, Cambodia
}

\author{
Liny SEK ${ }^{1}$, Aimee A. Sheree Barrion ${ }^{1}$, Clarissa B. Juanico ${ }^{1}$, Josefina T. \\ Dizon $^{2}$ \& Hurtada A. Wilma ${ }^{1}$
}

${ }^{1}$ Institute of Human Nutrition and Food, College of Human Ecology, University of the Philippines Los Banos; ${ }^{2}$ College of Public Affairs and Development, University of the Philippines Los Banos

\begin{abstract}
Introduction: There is a high prevalence of malnutrition in Cambodia during the past 10 years. One of the programmes implemented to secure household food security in order to alleviate malnutrition was home gardening. This study aimed to compare the nutritional status of 2 to 5 years old children in households with and without home gardens. Methods: Twenty-five households with home gardens and 60 households without home gardens were sampled. Results: The households sampled had a mixed type of home garden with three to five crop varieties occupying 20 to 200 square meters area. The purpose of the garden was to increase vegetable consumption and produce additional income. Results showed that $72 \%$ and $65 \%$ of the children resided in households with and without home gardens, respectively. Majority had medium dietary diversity score, i.e. consumed four to five different food groups per day. Except for stunting, higher prevalences of undernutrition $(32 \%)$ and wasting $(8 \%)$ were observed among children residing in households with home gardens compared to children in households without home gardens. Conclusion: There were no associations for dietary diversity score and nutritional status of children from households with and without home gardens. Among the sociodemographic and economic factors, age, sex, family size, and vegetable consumption were significantly associated with dietary diversity score and nutritional status of the children.
\end{abstract}

Keywords: Home garden, dietary diversity score, nutritional status

\section{INTRODUCTION}

Malnutrition (stunting and wasting) in Cambodia remains a critical issue, with significant numbers of undernourished children and women from all levels of income, especially in the rural areas (National Institute of Statistics, 2014). This problem is reported to be caused by factors such as limited social protection for the poor and vulnerable families, the inability of households to secure sufficient and nutritious foods due to high rural poverty, and the occurrence of natural disasters such as flooding and droughts (Chaparro, 2014). Approximately $32 \%$ and $9 \%$ of

\footnotetext{
*Corresponding author: Liny SEK, Lecturer

c/o institute of Human Nutrition and Food, College of Human Ecology,

University of the Philippines Los Banos

Tel: (855)87 294 977; E-mail: linysek94@gmail.com

doi: https: / / doi.org/10.31246/mjn-2020-0041
} 
children under 5 years were assessed to be stunted and severely stunted, respectively. High prevalence of stunting $(37 \%)$ was also observed in children with less than 24 months of birth interval. Wasted and severely wasted children under 5 years of age were reported at $10 \%$ and $2 \%$, respectively. The prevalence of wasting among children of underweight mothers was noted to be more than twice of those children with mothers of either normal or overweight nutritional status. Underweight in children under age 5 was 24\%, with $5 \%$ being severely underweight. Children who were born from mothers with the lowest wealth quintile were more likely to be underweight compared to children born from mothers in the highest wealth quintile. A total of $2 \%$ of children below age 5 were reported to be overweight. It was also reported that overnutrition among children tends to decrease with increasing age (National Institute of Statistics, 2014). It was assumed that overweight in young children was greater than in adults (National Institute of Statistics, 2014).

Approaches to reduce malnutrition in Cambodia include multi-sectoral efforts that cover the following: improving access to safe water supply, sanitation, and hygiene; increasing access to more diverse foods for women and children; addressing suboptimal infant and young child feeding (IYCF) practices; and supporting livelihood and social safety net (National Institute of Statistics, 2010). Since 1996, both government and non-government agencies in Cambodia have proposed different strategies, plans, and policies to reduce malnutrition among young children, majority of which had been funded by the United States Agency for International Development (USAID) (USAID, 2014). Home gardening was one of the proposed nutrition and food security projects in Cambodia, implemented mostly in the rural areas. A home garden is an area where vegetables, annual and perennial plants, spices, herbs, shrubs, and fruits are grown seasonally or throughout the year to meet family requirements (Van der Stege, 2009; Nordin, 2005; Gari, 2004; Helen Keller International, 2003; Midmore et al., 1991). Around 40 organisations are involved in vegetable production or home gardening activities. The Food and Agriculture Organization (FAO) recognises the important benefits of a home garden beyond the access to nutritional foods, which includes fuel for cooking, wood for building, medicinal plants, and additional income. In 2013, the home gardening project, funded by the USAID, was initiated in Siem Reap, and was also used as a tool to advocate conservation agriculture with women in Siem Reap. Initially, 15 farmers from three different districts participated in the Sustainable Agricultural and Natural Resource Management (SANREM) programme, in partnership with the Agricultural Development Denmark Asia (ADDA), which focused on conservation agriculture and irrigation technologies. This initial project by the University of California Davis (UC Davis) Horticulture Innovation Lab ended in late 2014, but USAID Center of Excellence of Sustainable Agriculture Intensification and Nutrition (CESAIN) continued it in 2015 with the previous 15 farmers, as well as an additional 40 selected farmers. The project aims to secure agricultural sustainability through conservation agriculture and to improve food security, dietary diversity, as well as income. With that, this study aimed to compare the dietary diversity and nutritional status of children aged 2 to 5 years in households with and without home gardens in Siem Reap province, Cambodia.

\section{MATERIALS AND METHODS}

\section{Study area}

Siem Reap province was selected as the study area as the home gardening project was implemented in different 
districts of Siem Reap since 2013. Based on the study of LEAP \& DIME Project (2011), Siem Reap is the poorest province in Cambodia with $28.6 \%$ of the total households belonging to Poor 1 and Poor 2 levels, characterised by a shortage of properties, lack of investment and productivity, and inaccessibility to the market. Siem Reap province is located in the northwestern part of Cambodia, surrounded by Battambong, Bantey Meanchey, Kompong Thom, Preah Vihear, and Oddor Meanchey provinces. Siem Reap has a total land area of $10,299 \mathrm{~km}^{2}$, which is divided into 12 districts, 100 communes, and 924 villages (GPCC, 2008). The total population of the province is 139,458 (World Population Review, 2018). The nutritional status of young children in Siem Reap has been a concern. The 2014 Cambodia Demographic Health Survey (CDHS) (National Institute of Statistics, 2014) reported that the prevalence of stunting is significantly higher among children living in poor households $(42 \%)$ than children living in moderate and rich households (19\%). Based on FAO's conceptual framework (FAO, 1999), poverty may strongly affect the nutritional status and food security in a family.

\section{Research design}

Case-control study was utilised for this research. The respondents of the study composed of households with and without home gardens, and with 2 to 5 years old children. Twenty-five households that have been implementing the home gardening project since 2013 were sampled from three districts, namely Prasat Bakong, Pouk, and Sot Nikom in the Siem Reap province. A complete enumeration of these 25 households with home gardens and 2 to 5 years old children was done. A total of 60 households without home gardens were also randomly selected from these three districts. This sampling number was computed based on the set value of $95 \%$ level of confidence, $8 \%$ sampling error, and the proportion of stunting at $32 \%$.

\section{Data collection}

Demographic and socio-economic profile of caregiver

The questionnaire format was patterned from the CDHS. The questions included the date of birth, sex of the child, civil status, educational attainment of the caregiver and household head, child's caregiver, occupation, living standard, source of income, expenditure, and household size. Living standards of the household were categorised into three categories: poor 1, poor 2, and moderate. Poor 1 and poor 2 levels were focused on families that had the poverty identification card provided by the government based on unavailability of properties, shortage of investment and productivity, and unreachability to the market. The mothers or caregivers of children were interviewed about the demographic and socio-economic status of the family, home garden information, and dietary intake for the last 24 hours before the interview. The children were measured for their anthropometric data (weight and height).

\section{Characteristics of the family's home garden}

Home gardening is an agro-ecosystem and a traditional land use practice carried out around a homestead consisting of mixed planting of herbs and species, leafy vegetables, roots, fruits, shrubs, grasses in a small plot to provide food, spices, medicines, and construction materials that are grown and maintained by the family members. The households in the project were interviewed for information related to home gardening. Size, variety of vegetables, frequency of vegetable consumption from home 
garden, vegetable income, and budget expenditure on foods were included in the questionnaire.

\section{Assessment of dietary intake}

Three days (2 weekdays, 1 weekend) of 24-hour food recalls were collected to determine dietary intake. The dietary diversity score questionnaire was used for data collection. The eight food groups considered for dietary diversity score included: 1) grains, roots or tubers; 2) vitamin A-rich plant foods; 3) other fruits or vegetables; 4) meat, poultry, fish, seafood; 5) egg; 6) pulse, legumes, nut, and seed; 7) milk and milk products; 8) foods cooked in oils or fats. The questionnaire used was based on the FAO guidelines (FAO 2010). The qualitative interpretation of dietary diversity was done by three classes: low dietary diversity ( $\leq 3$ food groups), medium dietary diversity (4 to 5 food groups), and high dietary diversity ( $\geq 6$ food groups).

\section{Anthropometric measurements}

The weight and height of 2 to 5 years old children were measured. Weight measurements were collected using a balance weighing scale provided by the village coordinator, supported by the Ministry of Health. Weight was obtained following protocols such as minimal clothing and emptying of pockets. Height measurements were carried out using a measuring board, following guidelines by the United Nations Children's Fund (UNICEF), with children measured in a standing position. Protocols such as heels, buttocks, scapula and occiput of the head in a straight line, with measuring board touching the head in Frankfort position, hand relaxed on the sides were strictly observed. Recording of weight was done to the nearest $100 \mathrm{~g}$, while height was measured to the nearest $0.1 \mathrm{~mm}$. Three nutritional indices were calculated using the children's age, height, and weight, which were then converted to sex-specific $z$-scores using the World Health Organization (WHO) AnthroPlus software. Children with weight-for-age, height-for-age, and weight-for-height between -2 standard deviation $(S D)$ to $+2 S D$ were classified as normal, while those with greater than $+2 S D$ were regarded as overweight, tall, and obese, and those with $z$-scores between $-3 S D$ to $-2 S D$ were classified as underweight, stunted and wasted (WHO, 1995).

\section{Statistical analysis}

Statistical Package for Social Sciences (SPSS) for Windows version 20 and Microsoft Excel were used for data entry and data analysis. Frequencies and percentages were calculated for categorical variables, while means and standard deviations were used for continuous variables. Spearman's test was used to correlate dietary diversity and nutritional status with age, respondent's education level, family size, monthly income factors, and vegetable consumption. On the other hand, Cramer's V was used to correlate dietary diversity and nutritional status with sex, child's caregiver, and respondent's occupation. The level of statistical significance for all analyses was set at $p<0.05$.

\section{RESULTS}

\section{Respondents' socio-demographic and economic characteristics}

Results of the study (Table 1) showed that majority of respondents from households with and without home gardens were young adult females, married, and had primary education. Respondents' age ranked from 20-69 years old, with an average of 35 years old. The average household size was five. Mother was a child's main caregiver. Eighty-four and 78 percent of the households with and 
Table 1. Socio-demographic and economic characteristics of respondents $(n=85)$

\begin{tabular}{|c|c|c|c|c|c|c|}
\hline \multirow{2}{*}{ Variable } & \multicolumn{2}{|c|}{ With } & \multicolumn{2}{|c|}{ Without } & \multicolumn{2}{|c|}{ Total } \\
\hline & $n$ & $\%$ & $n$ & $\%$ & $n$ & $\%$ \\
\hline \multicolumn{7}{|l|}{ Sex } \\
\hline Male & 4 & 16 & 4 & 7 & 8 & 9 \\
\hline Female & 21 & 84 & 56 & 93 & 77 & 91 \\
\hline \multicolumn{7}{|l|}{ Age (years) } \\
\hline 20-39 (young adult) & 17 & 68 & 44 & 74 & 61 & 72 \\
\hline 40-59 (adult) & 8 & 32 & 13 & 22 & 21 & 24 \\
\hline 60-69 (old) & 0 & 0 & 3 & 5 & 3 & 4 \\
\hline \multicolumn{7}{|l|}{ Civil status } \\
\hline Married & 25 & 100 & 57 & 95 & 82 & 96 \\
\hline Widow/er & 0 & 0 & 3 & 5 & 3 & 4 \\
\hline \multicolumn{7}{|l|}{ Educational attainment } \\
\hline No education & 2 & 8 & 8 & 13 & 10 & 12 \\
\hline $\begin{array}{l}\text { Primary school } \\
\text { (Grades } 1 \text { to } 6 \text { ) }\end{array}$ & 11 & 44 & 33 & 55 & 44 & 52 \\
\hline $\begin{array}{l}\text { Secondary school } \\
\text { (Grades } 7 \text { to 9) }\end{array}$ & 10 & 40 & 14 & 23 & 24 & 28 \\
\hline $\begin{array}{l}\text { High school } \\
\text { (Grades } 10 \text { to } 12 \text { ) }\end{array}$ & 2 & 8 & 4 & 7 & 6 & 7 \\
\hline University & 0 & 0 & 1 & 2 & 1 & 1 \\
\hline \multicolumn{7}{|l|}{ Household size } \\
\hline $3-5$ & 17 & 68 & 50 & 83 & 67 & 79 \\
\hline $6-9$ & 8 & 32 & 10 & 17 & 18 & 21 \\
\hline \multicolumn{7}{|l|}{ Living standard of household } \\
\hline Poor 1 & 2 & 8 & 8 & 13 & 10 & 12 \\
\hline Poor 2 & 2 & 8 & 5 & 8 & 7 & 8 \\
\hline Moderate & 21 & 84 & 47 & 78 & 68 & 80 \\
\hline \multicolumn{7}{|l|}{ Child's caregiver } \\
\hline Mother & 16 & 64 & 43 & 72 & 59 & 69 \\
\hline Father & 2 & 8 & 1 & 2 & 3 & 4 \\
\hline Sibling & 0 & 0 & 1 & 2 & 1 & 1 \\
\hline Aunt & 1 & 4 & 2 & 3 & 3 & 4 \\
\hline Grandparents & 6 & 24 & 13 & 22 & 19 & 22 \\
\hline \multicolumn{7}{|l|}{ Occupation } \\
\hline Farmer & 20 & 80 & 39 & 65 & 59 & 69 \\
\hline Small business owner & 3 & 12 & 7 & 12 & 10 & 12 \\
\hline Garment worker & 0 & 0 & 2 & 3 & 2 & 2 \\
\hline Government official & 0 & 0 & 1 & 2 & 1 & 1 \\
\hline Casual labour & 1 & 4 & 2 & 3 & 3 & 4 \\
\hline Housewife & 1 & 4 & 4 & 7 & 5 & 6 \\
\hline Other & 0 & 0 & 5 & 8 & 5 & 6 \\
\hline \multicolumn{7}{|l|}{ Monthly income (riel) } \\
\hline $100,000-1,000,000$ riel & 12 & 48 & 41 & 68 & 53 & 62 \\
\hline $1,000,100-2,000,000$ riel & 8 & 32 & 14 & 23 & 22 & 26 \\
\hline $2,000,100-4,000,000$ riel & 4 & 16 & 3 & 5 & 7 & 8 \\
\hline $4,000,100-6,000,000$ riel & 1 & 4 & 2 & 3 & 3 & 4 \\
\hline
\end{tabular}


without home gardens, respectively, had a moderate living standard. Sixty-two percent of households had an income ranging from 100,000 to $1,000,000$ riel ( 25 to 250 USD), while the average income was $1,491,600$ riel $(372.89$ USD). Farming was the major source of income.

\section{Characteristics of home gardens}

In terms of a home garden, 19 households have been involved in the project for three to four years. Seed, water tank, and fertilisers were provided. The size of the garden ranged from 20 to 200 square meters and some were $>1000$ square meters. Vegetables were grown about three to four times per year. Green mustard, luffa, cucumber, water spinach, chilli and round brinjal were the main types of vegetables grown.
Vegetable gardening aims to increase vegetable consumption and provide additional income. A household could earn around 40,000 to $1,00,000$ riel (10 to 250 USD) from vegetable gardening.

\section{Dietary diversity score of the children}

With regards to dietary diversity score, 55 children had a medium score. Children from households without home gardens had higher low dietary diversity score than children from households with home gardens. Consumption of fruits, vegetables, meat and milk were higher among children residing in households with home gardens than in children residing in households without home gardens. Consumption of pulses/legumes or nut was not observed (Table 2).

Table 2. Dietary diversity score and nutritional status of children in households with and without a home garden

\begin{tabular}{lcccc}
\hline \multirow{2}{*}{ Variable } & \multicolumn{2}{c}{ With a home garden } & \multicolumn{2}{c}{ Without a home garden } \\
\cline { 2 - 5 } & $n$ & $\%$ & $n$ & $\%$ \\
\hline Dietary Diversity Score & 3 & 12 & 2 & 3 \\
High (6 and above) & 18 & 72 & 37 & 62 \\
Medium (4 to 5) & 4 & 16 & 21 & 35 \\
Low (below than 3) & & & & \\
Nutritional Status & & & 39 & 65 \\
Weight-for-age & 17 & 68 & 17 & 28 \\
Normal ( $\pm 2 S D)$ & 8 & 32 & 4 & 7 \\
Underweight $(<-2 S D)$ & 0 & 0 & & \\
Severely underweight $(<-3 S D)$ & & & 55 & 7 \\
Weight-for-height & 21 & 84 & 4 & 2 \\
Normal $( \pm 2 S D)$ & 2 & 8 & 1 & \\
Wasted $(<-2 S D)$ & 2 & 8 & & 50 \\
Severely wasted $(<-3 S D)$ & & & 30 & 33 \\
Height-for-age & 17 & 68 & 20 & 17 \\
Normal $( \pm 2 S D)$ & 5 & 20 & 0 & 0 \\
Stunted $(<-2 S D)$ & 2 & 8 & & \\
Severely stunted $(<-3 S D)$ & 1 & 4 & & \\
Tall $(>2 S D)$ & & & & \\
\hline
\end{tabular}




\section{Nutritional status of the children}

Underweight: Eight and 17 children from households with and without home gardens were underweight, respectively, while seven children residing in a household without home garden were severely underweight.

Wasting: Eight and seven percent of children from households with and without home gardens, respectively, were analysed to be wasted. Eight and two percent were severely wasted.

Stunting: Children in households with and without home gardens had $20 \%$ and $33 \%$ of stunting, respectively. Eight and 17 percent of the children were severely stunted.

\section{Relationship of home garden ownership with dietary diversity score and nutritional status of children}

Results of the study (Table 3) revealed that there were no significant differences in dietary diversity score, weight-forage, weight-for-height, and heightfor-age of children from households with and without a home garden. This outcome illustrated that the presence or absence of a home garden did not influence the dietary diversity and nutritional status of the children at the research sites. The similarities in living standard, household size, mother's educational attainment, and monthly income between households with and without home garden (Table 1), as well as the traditional home garden practice that have existed in these households without the project might have led them to have similar variety of food intakes and child feeding practices.

\section{Relationship between socio- demographic and economic factors with dietary diversity score and nutritional status of children}

\section{Dietary diversity score}

There was a negative, moderate significant association between dietary diversity score and age of the children from households with a home garden $(p=0.01, r=-0.49)$. This implied that the increase in respondent or caregiver's age tend to lower the dietary diversity score of children in the family. This may be supported by the results of Oduor's study in 2018 which explained that the age of the caregiver influences his/her nutritional knowledge and attitudes towards food preparation (Oduor, 2018). Young people tend to understand more about food choices, cooking methods, and the ability to get food for the family. However, there were no significant relationships between dietary diversity score and sex, child's caregiver, educational attainment, respondents' occupation, family size, income, and vegetable consumption of families without a home garden.

\section{Nutritional status}

There were no significant relationships between socio-demographic characteristics and economic factors with weight-

Table 3. Correlations between households with and without a home garden with dietary diversity score and nutritional status of children

\begin{tabular}{lcc}
\hline Variable & Coefficient & $P$-value \\
\hline Dietary Diversity Score & $0.235 \mathrm{~ns}$ & 0.01 \\
Weight-for-age (underweight) & $0.144 \mathrm{~ns}$ & 0.41 \\
Weight-for-height (wasting) & $0.160 \mathrm{~ns}$ & 0.33 \\
Height-for-age (stunting) & $0.253 \mathrm{~ns}$ & 0.14 \\
\hline
\end{tabular}


for-age and height-for-age of the children. However, family size $(p=0.01$, $r=0.5)$ and vegetable consumption of the family $(p=0.01, r=0.53)$ were found to have a positive and moderate significant association with weightfor-height (wasting) of the children with home gardens. This implied that the consumption of more vegetables may reduce the prevalence of wasting. Sex $(p=0.001, \quad r=0.53)$ had a positive, strong association, while family size $(p=0.02, r=-0.29)$ had a negative, very weak relationship with weight-for-height (wasting) of the children from households without a home garden (Table 4).

A large family size may result in more mouths to feed, thus decreasing the amount of available foods to feed the children. Food intake decreases per capita with an increase in family size (Vil, 1975). Studies have shown that the foods available per head to larger families were often lower than that available to smaller families, and this unequal food distribution reflected growth rate. Moreover, the nutrient intakes of the children were observed to be lower than the recommended dietary intake for children aged 2 to 5 years old (FNRIDOST, 2015). Energy, protein and fat intakes of the children were significantly associated with the nutritional status of the children. Low food and nutrient intakes influence the growth of children.
Protein intake in particular is important for growth because protein provides essential amino acids required for protein synthesis. Hence, deficiency of protein will limit a child's growth significantly (Braun, 2016).

\section{DISCUSSION}

The results of the nutritional status of children at the research sites were similar to a survey conducted by the Cambodia Demographic and Health Survey in 2014 in Siem Reap. About $35.9 \%$ of the children were reportedly stunted, while $11.3 \%$ were severely stunted. The majority were underweight $(26.2 \%)$ and $6.4 \%$ consisted of those who were severely underweight; $9.5 \%$ existed in a wasted situation, and 2.3\% were severely wasted (National Institute of Statistics, 2014). The probable causes of underweight were identified as follows: inadequate food consumption, an underlying illness, stress, obsessive exercise, lack of interest in eating, or a sudden growth spurt. Low mean energy intake of $653 \mathrm{kcal}$ (with home garden) and 640kcal (without a home garden) among the children respondents were observed. These were much lower in comparison to the recommended energy intake for males aged 1 to 2 years and 3 to 5 years old at $1000 \mathrm{kcal}$ and $1350 \mathrm{kcal}$, respectively, as well as the recommended

Table 4. Relationship of socio-demographic and economic factors with dietary diversity score of children

\begin{tabular}{lcccc}
\hline \multirow{2}{*}{ Variable } & \multicolumn{2}{c}{ With } & \multicolumn{2}{c}{ Without } \\
\cline { 2 - 5 } & Coefficient & P-value & Coefficient & P-value \\
\hline Age & $-0.49^{*}$ & 0.01 & 0.08 & 0.56 \\
Respondent's education level & 0.18 & 0.38 & 0.08 & 0.52 \\
Family size & -0.01 & 0.94 & 0.11 & 0.39 \\
Monthly income & -0.27 & 0.20 & 0.07 & 0.58 \\
Sex & 0.18 & 0.66 & 0.92 & 0.77 \\
Child's caregiver & 0.44 & 0.15 & 0.23 & 0.64 \\
\hline
\end{tabular}

*Correlation is significant at $p<0.05$ 
energy intake for females aged 1 to 2 years and 3 to 5 years at 930kcal and 1260 kcal, respectively (FNRI-DOST, 2015). In addition, the nutrients intake of the children from this study also showed that majority had low nutrients intake per day. Wasting, or low weightfor-height, is characterised as the failure to receive adequate nutrition in the period immediately preceding a survey, and a result of inadequate food intake or a recent episode of illness that has caused loss of weight and the onset of malnutrition (WHO, 2018). Research in Tanzania (Mgongo et al., 2017) and Western Kenya (Bloss et al., 2004) have found that children who had illnesses were more likely to have low weightfor-height (wasting). Wasting is a strong predictor of mortality among children under five years of age. Stunting, on the other hand, can begin before birth as a result of a mother's poor nutritional status and continues after birth if a mother cannot provide high quality breast milk. These undesirable conditions can make an undernourished child more likely to become sick.

According to the data of a district situation in 2015 for management and development, it was stated that farming is the main occupation of the people in the study area $(86.36 \%)$. Women are major contributors, with other family members, in earning income for family support. Home gardening is a part of food consumption and family income. Low-income families were prioritised by the USAID (CESIAN) home gardening project to serve food security and consequently acquire income and health. Interestingly, majority of the households $(73 \%)$ at the research sites had their own gardens even though they were not in the gardening project. Their gardens had an average size land of 160 meters square. They simply grew white Chinese cabbage, water spinach, herbs, green mustard, luffa gourd and so on.

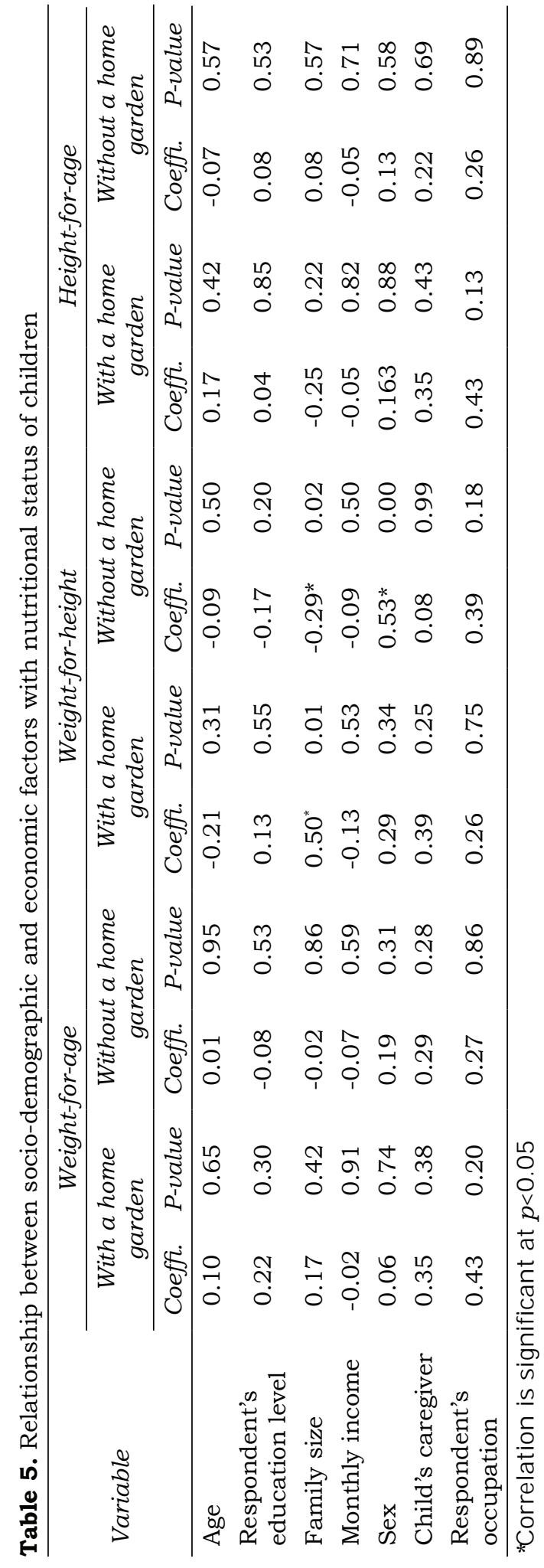


Thus, there were many similarities in socio-demographic and economic characteristics of households with and without home gardens (educational attainment, occupation, income, etc.). Table 4 implies that there were no significant associations of some sociodemographic factors with dietary diversity score and nutritional status of the children. However, there were slightly higher prevalences of underweight, wasting, and severe wasting in children from households with a home garden in comparison to children from households without a home garden. Nevertheless, there is a possibility that these children may have had higher wasting and underweight rates than at present, before their families got involved in the project.

\section{CONCLUSION}

There were no associations between dietary diversity scores and nutritional status of children with and without home gardens. Among the socio-demographic and economic factors, age, sex, family size, and vegetable consumption were significantly associated with dietary diversity score and nutritional status of the children.

\section{Acknowledgement}

The authors would like to thank the Southeast Asian Regional Center for Graduate Study and Research in Agriculture (SEARCA) and CESAIN for their support in this research.

\section{Authors' contributions}

LS, led the data collection, conducted the study, data analysis and interpretation, prepared the draft of the manuscript and reviewed the manuscript; ASB, advised on study methodology, provided advice and reviewed the manuscript; CBJ, JTD and WAH, provided advice and reviewed the manuscript.

\section{Conflict of interest}

There is no conflict of interest to declare.

\section{References}

Adventis Development and Relief Agency Cambodia (ADRA) (2018). Food Security \& Nutrition for All (FSNFA). From http://www.adracambodia. org. [Retrieved January 1, 2019].

Bloss E, Wainaina F \& Bailey RC (2004). Prevalence and predictors of underweight, stunting, and wasting among children aged 5 and under in Western Kenya. School of Public Health and Tropical Medicine, Tulane University, New Orleans, LA, USA. J Trop Pediatr 50:260-270.

Braun KV, Erler NS, Kiefte-De Jong JC, Jaddoe VW, van den Hooven EH, Franco OH \& Voortman T (2016). Dietary intake of protein in early childhood is associated with growth trajectories between 1 and 9 years of age. $J$ Nutr 146(11):2361-2367.

Cabalda AB, Rayco-Solon P, Solon JA \& Solon FS (2011). Home gardening is associated with Filipino preschool children's dietary diversity. J Am Diet Assoc 111: 711-715. doi: 10.1016/j. jada.2011.02.005.

CESAIN \& RUA (2016). Biophysical assessment of Conservation Agriculture Systems in the uplands and lowlands. Center of Excellence on Sustainable Agricultural Intensification and Nutrition (CESAIN) \& Soil Lab, Royal University of Agriculture, Phnom Penh, Cambodia.

Chaparro C, Oot L \& Sethuraman K (2014). Cambodia Nutrition Profile. FHI 360/FANTA, Washington DC.

FAO (2010). Guidelines for Measuring Household an Individual Dietary Diversity (reprinted in 2013). Food and Agriculture Organization, United Nations, New York.

FNRI-DOST (2015). Philippine Dietary Reference Intakes. Food and Nutrition Research Institute, Department of Science and Technology, Philippines.

Gari JA (2004). Agrobiodiversity Strategies to Combat Food Insecurity and HIV/AIDS Impact in Rural Africa, preliminary edition (pp. 154). FAO (Population and Development Service), Rome, Italy.

General Population Census of Cambodia (2008). National Report on Final Census Results. National Institute of Statistics. Ministry of Planning, Phnom Penh, Cambodia.

Helen Keller International (2003). Handout of Home Gardening in Cambodia. The complete manual for vegetable and fruit production. Helen Keller Worldwide, Phnom Penh. 
LEAP \& DIME (2011). Impact evaluation of LEAP project on the livelihood of the poor in Siem Reap, Cambodia, LEAP project: Livelihood Enhancement \& Association of the Poor in Siem Reap. Livelihood Enhancement \& Association of the Poor, Cambodia.

Meinzen-Dick R, Behrman J, Menon R \& Quisumbing A (2011). Gender: A key dimension linking agricultural programs to improved nutrition and health. 2020 Conference Brief 9. IFPRI, Washington DC.

Mgongo M, Chotta NAS, Hashim TH, Uriyo JG, Damian DJ, Stray-Pedersen B, Msuya SE, Wandel M \& Vangen S (2017). Underweight, stunting and wasting among children in Kilimanjaro region, Tanzania; a populationbased cross-sectional study. Int J Env Res Pub He 14(5):509.

Midmore DJ, Niñez V \& Venkataraman R (1991). Household gardening projects in Asia: past experience and future directions. AVRDC Technical Bulletin No. 19. AVRDC, Shanhua, Taiwan Province of China.

National Institute of Statistics (2014). Cambodia Demographic and Health Survey (CDHS). National Institute of Statistics, Ministry of Planning and Ministry of Health, Phnom Penh, Cambodia.

National Institute of Statistics (2010). Cambodia Demographic and Health Survey (CDHS). National Institute of Statistics, Ministry of Planning and Ministry of Health, Phnom Penh, Cambodia.
Nordin S (2005). Per culture Network of Malawi. Personal Communication with Stacia Nordin World Food Program, Malawi, November 2005.

Oduor FO, Boedecker J, Kennedy G, MitukiMungiria D \& Termote C (2018). Caregivers' nutritional knowledge and attitudes mediate seasonal shifts in children's diets. Matern Child Nutr 15:1-10. doi:10.1111/mcn.12633.

UNICEF (2017). Undernutrition contributes to nearly half of all deaths in children under 5 and is widespread in Asia and Africa. United Nations Children's Fund. From http://data. unicef.org/topic/nutrition/malnutrition/. [Retrieved January 1 2018].

Van der Stege C (2009). Cuban Home Gardens and Their Role in Social-Ecological Resilience. Hum Ecol 37: 705-721. doi:10.1007/s10745-0099283-9.

Vis HL, Yourasowsky C \& Van Der Borght $H$ (1975). A nutritional survey in the Republic of Rwanda. Brussells: Musée Royal de l'Afrique Centrale. Tervaren, Belgique. Annales-Serie In8, Sciences Humaines 1975.

WHO (2018). Fact sheet: Malnutrition. World Health Organization. From https://www.who.int/ news-room/fact-sheets/detail/malnutrition. [Retrieved January 2 2018].

World Population Review (2018). Cambodia Population. From http:// worldpopulationreview.com/countries / cambodia-population. [Retrieved January 1 2019]. 